\title{
Quantification of pulmonary vessel volumes on low-dose computed tomography in a healthy male Chinese population: the effects of aging and smoking
}

\author{
Xuebiao Sun ${ }^{1 \#}$, Xiapei Meng ${ }^{1 \#}$, Peiyao Zhang ${ }^{1}$, Lei Wang ${ }^{1}$, Yanhong Ren ${ }^{2}$, Guodong Xu ${ }^{3}$, Ting Yang ${ }^{2}$, \\ Min Liu ${ }^{1}$ \\ ${ }^{1}$ Department of Radiology, China-Japan Friendship Hospital, Beijing, China; ${ }^{2}$ Department of Pulmonary and Critical Care Medicine, China-Japan \\ Friendship Hospital, Beijing, China; ${ }^{3}$ Institute of Clinical Medicine, China-Japan Friendship Hospital, Beijing, China
}

Contributions: (I) Conception and design: M Liu, Y Ren, T Yang; (II) Administrative support: M Liu; (III) Provision of study materials or patients: P Zhang, L Wang, Y Ren, T Yang; (IV) Collection and assembly of data: X Sun, X Meng; (V) Data analysis and interpretation: X Sun, X Meng, P Zhang, G Xu; (VI) Manuscript writing: All authors; (VII) Final approval of manuscript: All authors.

"These authors contributed equally to this work.

Correspondence to: Min Liu. 2 Yinghua Dong Street, Hepingli, Chao Yang District, Beijing 100029, China. Email: drradiology@163.com.

Background: This study sought to determine pulmonary vascular volumes (PVVs) on low-dose computed tomography (LDCT) in a healthy male Chinese population and analyze the effects of aging and smoking on PVVs.

Methods: A total of 1,320 healthy male participants (comprising 720 non-smokers, 445 smokers, and 155 ex-smokers) who underwent LDCT were retrospectively included in this study. Their demographic data and smoking status data were collected. An automatic integration segmentation approach for LDCT was used to segment pulmonary vessels semi-automatically. The PVVs of the whole lung, left lung, and right lung on LDCT were calculated, and correlations between PVVs and age and smoking status were then compared.

Results: The inter-rater correlation coefficient of the whole lung, left lung, and right lung PVVs was 0.98 [95\% confidence interval (CI): 0.95-0.99], 0.97 (95\% CI: 0.93-0.98), and 0.97 (95\% CI: 0.94-0.99), respectively. The intra-class correlation coefficient of the whole lung left lung, and right lung PVVs was 0.98 (95\% CI: 0.95-0.99), 0.96 (95\% CI: 0.95-0.99), and 0.96 (95\% CI: 0.92-0.98), respectively. In non-smokers, PVVs decreased with age. The PVVs of heavy smokers were higher than those of light smokers, ex-smokers, and non-smokers. The PVVs of ex-smokers were comparable to those of light smokers.

Conclusions: The PVVs measured on LDCT tended to decrease with age in healthy male non-smokers gradually. Compared to non-smokers, the PVVs of smokers increased, even with the normal lung function.

Keywords: Pulmonary vascular volumes (PVVs); low-dose computed tomography (LDCT); aging; smoking

Submitted Feb 07, 2021. Accepted for publication Jun 24, 2021.

doi: 10.21037/qims-21-160

View this article at: https://dx.doi.org/10.21037/qims-21-160 


\section{Introduction}

Aging is a physiological phenomenon of the human body, and each system of the body, including the respiratory system, undergoes many age-associated changes (1). The pulmonary disease has significant consequences for the aging population. Cigarette smoking is a risk factor for many diseases $(2,3)$ and is associated with vascular endothelial dysfunction, the increased expression of growth factors, and inflammatory cell infiltration in pulmonary arteries (4). Animal experiments have shown that pulmonary vascular remodeling precedes emphysema $(5,6)$, indicating that smoking may cause damage to the pulmonary vasculature at an early stage. In the Multi-Ethnic Study of Atherosclerosis (MESA) study (7), chest computed tomography (CT) indicated that ever-smokers (people who used to smoke but quit smoking for more than one year) had higher pulmonary vascular volumes (PVVs) than neversmokers (people who never smoke). Similarly, tobacco exposure was found to be consistently associated with high absolute PVVs in the Framingham Heart Study (8). However, these studies were conducted using highresolution CT, which raised concerns about the highradiation exposure of subjects.

Currently, low-dose computed tomography (LDCT) is being used to screen early lung cancer, chronic obstructive pulmonary disease (COPD), and cardiovascular disease (9-11). However, the manual extraction process used by radiologists to segment pulmonary vessels in LDCT images is time-consuming. Tan et al. (12) proposed an automatic integration segmentation approach for vascular trees in CT scans. Jun et al. (13) applied an automatic integration segmentation approach for vascular trees in LDCT scans. However, to date, no one has examined whether PVVs can be quantified on LDCT images. Further, the correlations between PVVs and aging and smoking require further study. Thus, the present study sought to (I) calculate PVVs on LDCT scans and examine alterations in PVVs in healthy non-smokers concerning age; (II) analyze alterations in PVVs among different types of smokers (e.g., non-smokers, light smokers, heavy smokers, and ex-smokers).

\section{Methods}

\section{Study cohort and design}

Participants attending health check-ups at the physical examination center of our hospital from January 2017 to December 2019 were enrolled in this retrospective study.
Figure 1 provides a flowchart detailing how participants were selected. To be eligible to participate in this study, people must meet the following inclusion criteria: (I) be aged 40 years or older; (II) have undergone a lung function examination and LDCT in the same day; (III) have normal lung function, and routine blood and urine tests, thyroid hormone levels, and electrocardiography according to the health check-up reports. Patients were excluded from the study if they met any of the exclusion criteria: (I) were female; (II) had a spinal or thoracic deformity; (III) had a history of chest or cardiac surgery; (IV) had previously had tuberculosis or systemic disease; (V) had cancer, liver or kidney dysfunction; and/or (VI) had obvious respiratory or motion artifacts, a lung mass $>3 \mathrm{~cm}$ in diameter, a lung infection, an interstitial lung disease, or bronchiectasis according to the LDCT.

The study was approved by the Ethics Committee of the China-Japan Friend Hospital (IRB 2019-123-K85-1). The study was conducted in accordance with the Declaration of Helsinki (as revised in 2013). Informed consent was obtained from all patients.

A smoking history (including cigarette consumption and the duration of smoking or the smoking-cessation period in years) was collected from the health check-up reports for each subject. The subjects were classified as non-smokers, smokers (if they had been smoking for $>1$ year), and exsmokers (if they had stopped smoking for $>1$ year). Based on their smoking status (14), smokers were classified as light smokers ( $\leq 20$ packs/year) or heavy smokers (>20 packs/year).

\section{LDCT}

LDCT was performed on a 256-slice spiral CT scanner (Brilliance CT, Phillips Healthcare, Netherlands). All subjects were examined at full inspiration in the supine position without contrast material injection. Helical scanning was performed in the craniocaudal direction with a beam pitch of 0.993 . The tube settings were $100-120 \mathrm{kVp}$ and 50-80 mAs with DoseRight Angular Dose Modulation according to each patient's weight, and the rotation time was 0.5 seconds. Thin-section images were reconstructed with $1-\mathrm{mm}$ thick slices at $0.9-\mathrm{mm}$ intersection intervals. The matrix size was $512 \times 512$ pixels (a soft reconstruction kernel was used for the lung).

\section{Segmentation of pulmonary vessels on LDCT}

The included participants were divided into 1 of the 


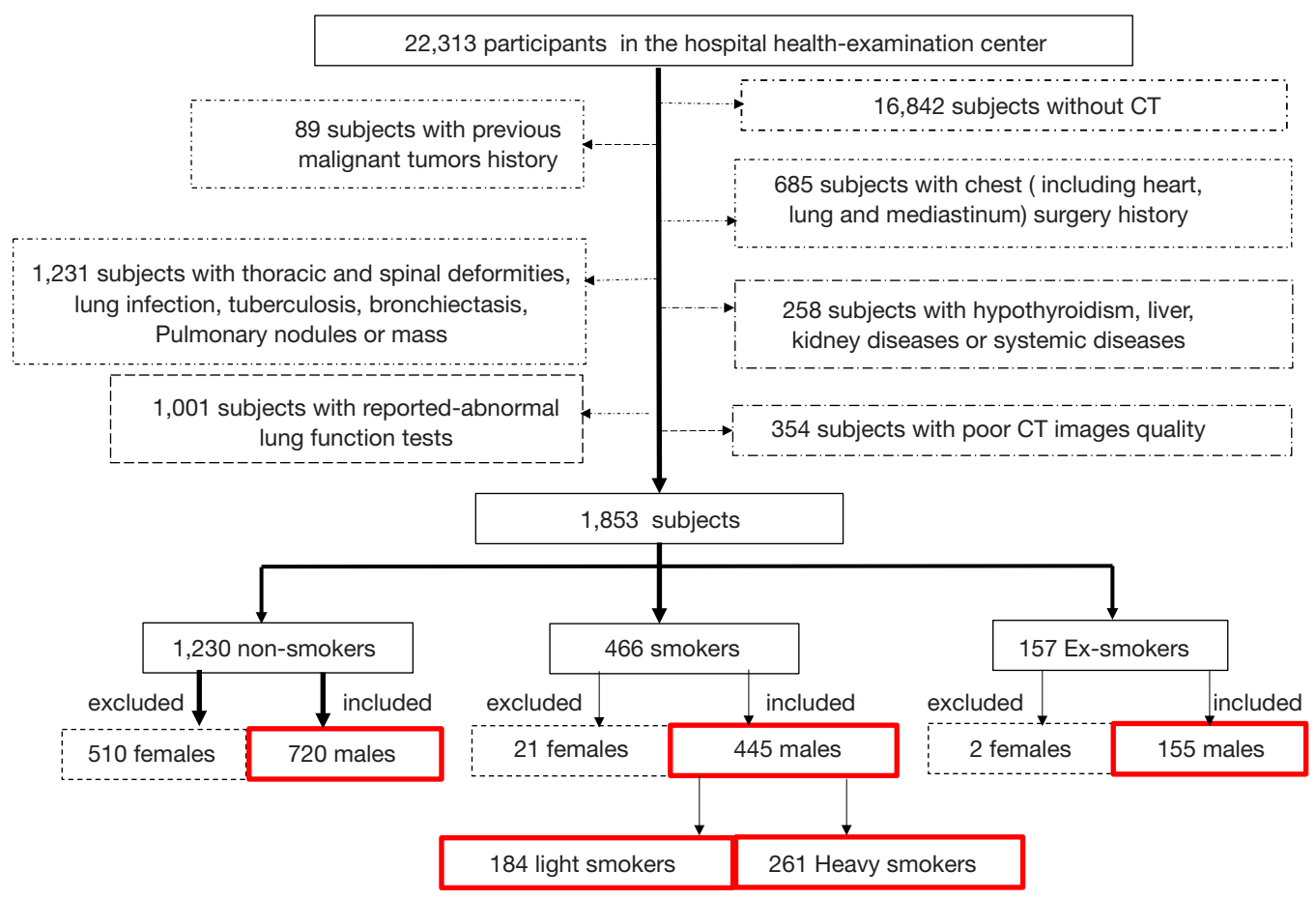

Figure 1 Flowchart detailing how participants were selected.

following 4 groups based on age: (I) the 40-49-year-old group; (II) the 50-59-year-old group; (III) the 60-69-yearold; or (IV) the $\geq 70$-year-old group. PVVs of the 4 groups were independently analyzed by 4 chest radiologists (1 with 8 -year experience and the other 3 with 10 -year experience).

LDCT images in Digital Imaging and Communications in Medicine (DICOM) format were transferred to a threedimensional (3D) in-home workstation (FACT AI+digitalLung V1.0, Shenzhou Dexin Medical Imaging Technology Co., Ltd., Weinan Shanxi, China), and pulmonary vessels were semi-automatically segmented using an automatic integration segmentation approach (13). The following basic principles and steps were used (see Figure 2). First, the lung was segmented from the soft tissue using an adaptive border marching algorithm (15), and a computational geometry approach was used to segment automated pulmonary fissures and the 5 pulmonary lobes $(16,17)$. Second, as LDCT scans have increased density noise, a soft 3D Gaussian kernel filter was used to reduce density noise. Third, an adaptive threshold was applied to segment the specific scans to identify the seeds of the pulmonary vascular trees. Fourth, a quick multi-seed $3 \mathrm{D}$ region growing algorithm was used to identify the pulmonary vascular trees. Fifth, the implicit integration and curvature flow method were used to smooth pulmonary vascular trees, and a "puzzle game" procedure was applied as a correction operation to filter false identifications (18). Finally, the results of the automatic segmentation of the pulmonary vascular trees were reviewed by radiologists, who made manual corrections to any improper vascular segmentation, and the PVVs were then automatically displayed. Segmentation and the review and manual correction of each case took 10-20 minutes.

\section{Statistical analysis}

All statistical analyses were performed using SPSS 22.0 (SPSS Inc, Chicago, IL, USA) and MedCalc (MedCalc Version 18.11. Acacialaan 22, Ostend, Belgium). All the data are expressed as means \pm standard deviations (SDs). To test the reproducibility of the PVV measurements as determined by LDCT, 30 subjects were randomly selected from the enrolled subjects and their PVVs were analyzed independently by 2 experienced radiologists and evaluated again 2 weeks later by 1 radiologist with BlandAltman plots. The intra-class correlation method was used to examine intra- and inter-observer variation. A 1-way 

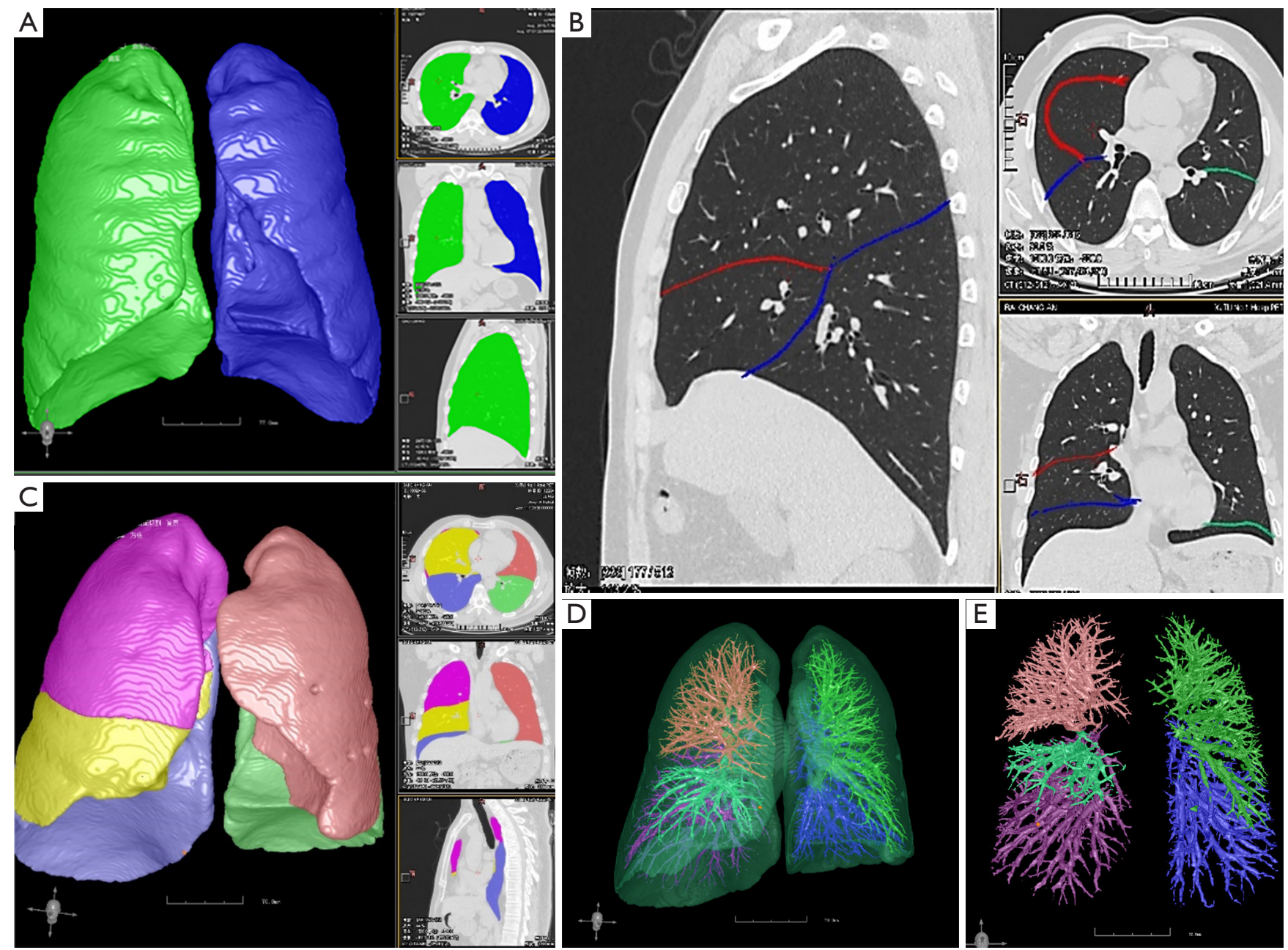

Figure 2 Segmentation of pulmonary vascular trees. (A) An adaptive border marching algorithm was used to separate lung regions from soft tissue. (B) A computational geometry approach was used to automatically segment pulmonary fissures. (C) An adaptive border marching algorithm was used to separate the 5 pulmonary lobes. (D) A quick multi-seed 3D region growing algorithm was used to identify pulmonary vascular trees (different colors represent vascular trees in different lobes). (E) A 3D visualization of the computerized segmentation of the pulmonary vessels.

analysis of variance (ANOVA) was used to compare the whole lung, left lung, and right lung PVVs among the groups, and independent $t$-tests were used to compare any 2 groups. A $\mathrm{P}$ value $<0.05$ was considered statistically significant.

\section{Results}

\section{Subjects characteristics}

A total of 1,320 male subjects, comprising 720 nonsmokers, 445 smokers, and 155 ex-smokers, were enrolled in this study. Their baseline demographic data are presented in Table 1. Totally 445 smokers were classified as either light or heavy smokers, and each group was further divided according to age. The light-smokers group comprised 38 subjects aged $40-49$ years, 68 aged 50-59 years, 36 aged $60-69$ years, and 42 aged $\geq 70$ years. The heavy smokers comprised 26 subjects aged $40-49$ years, 132 aged 50-59 years, 96 aged $60-69$ years, and 7 aged $\geq 70$ years. There were 155 males in the ex-smoker group, comprising 5 subjects aged $40-49$ years, 44 aged $50-59$ years, 58 aged 60-69 years, and 48 aged $\geq 70$ years. The mean effective radiation dose of LDCT was $1.6 \pm 0.3 \mathrm{mSv}$. 
Table 1 Baseline demographic information of all participants

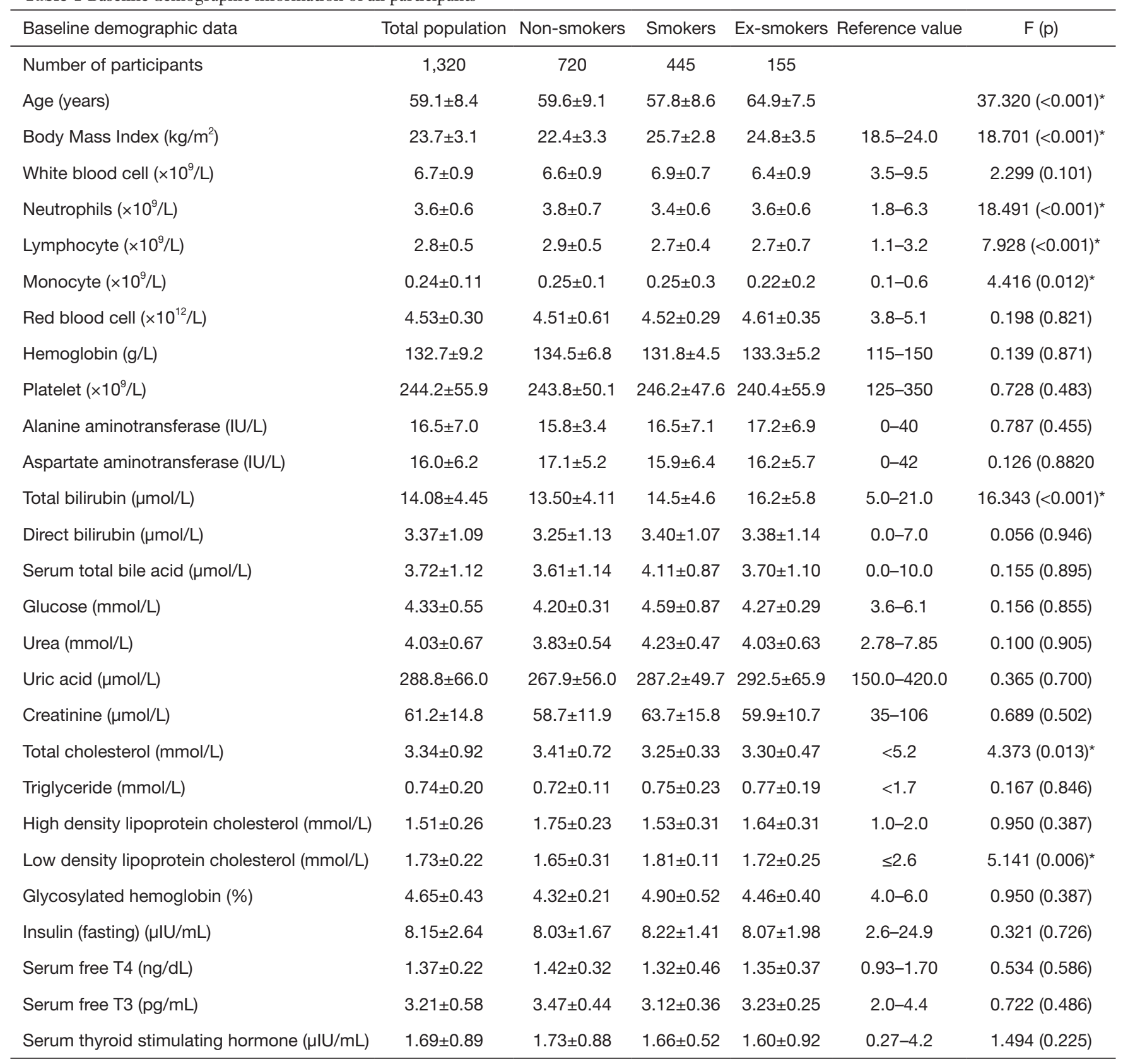

1-way ANOVA test with $\mathrm{F}$ value ${ }^{*} \mathrm{P}<0.05$.

\section{Reproducibility of PVV measurements}

The Bland-Altman plots of the whole lung PVVs (see Figure 3A), left lung PVVs (see Figure 3B), and right lung PVVs (see Figure $3 C$ ), as measured by 2 observers, demonstrated a bias of $0.7,0.4$, and 0.9 , respectively. The inter-rater correlation coefficient of the whole lung left lung, and right lung PVVs was 0.98 (95\% CI: 0.95-0.99), 0.97 (95\% CI: 0.93-0.98), and 0.97 (95\% CI: 0.94-0.99), respectively.

The Bland-Altman plots of the whole lung PVVs (see Figure 4A), left lung PVVs (see Figure 4B), and right lung PVVs (see Figure 4C), measured twice by the same observer within 1 month, showed a bias of $0.2,0$, and 0.3 , respectively. The intra-class correlation coefficient of the whole lung, left lung, and right lung PVVs was 0.98 (95\% 

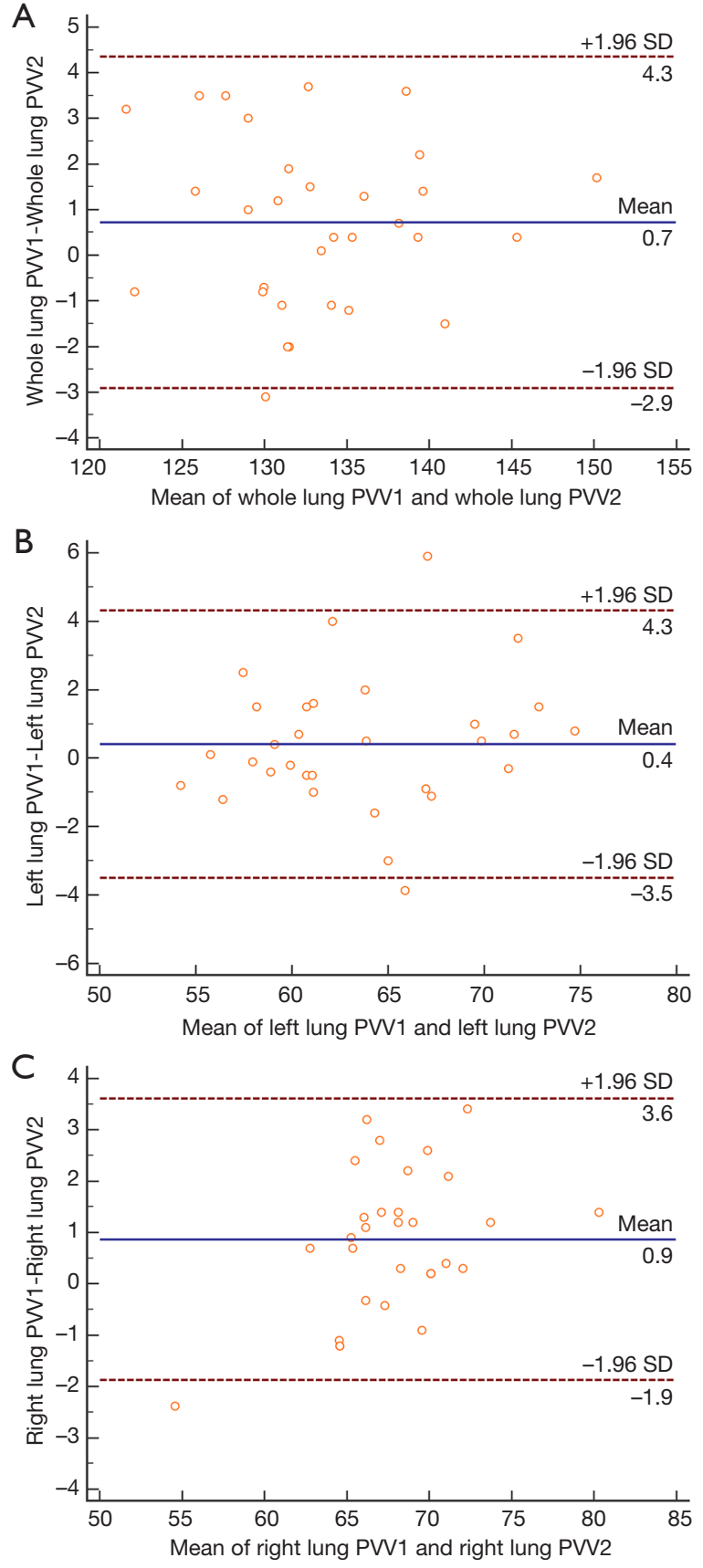

Figure 3 Bland-Altman plots of PVV measurements by 2 observers. (A) A Bland-Altman plot of the whole lung PVVs (as measured by 2 observers) demonstrated a bias of 0.7 . (B) A BlandAltman plot of left lung PVVs (as measured by 2 observers) demonstrated a bias of 0.4. (C) A Bland-Altman plot of right lung PVVs (as measured by 2 observers) demonstrated a bias of 0.9 . PVV1 and PVV2 represent the PVVs measured by observer 1 and observer 2 , respectively.
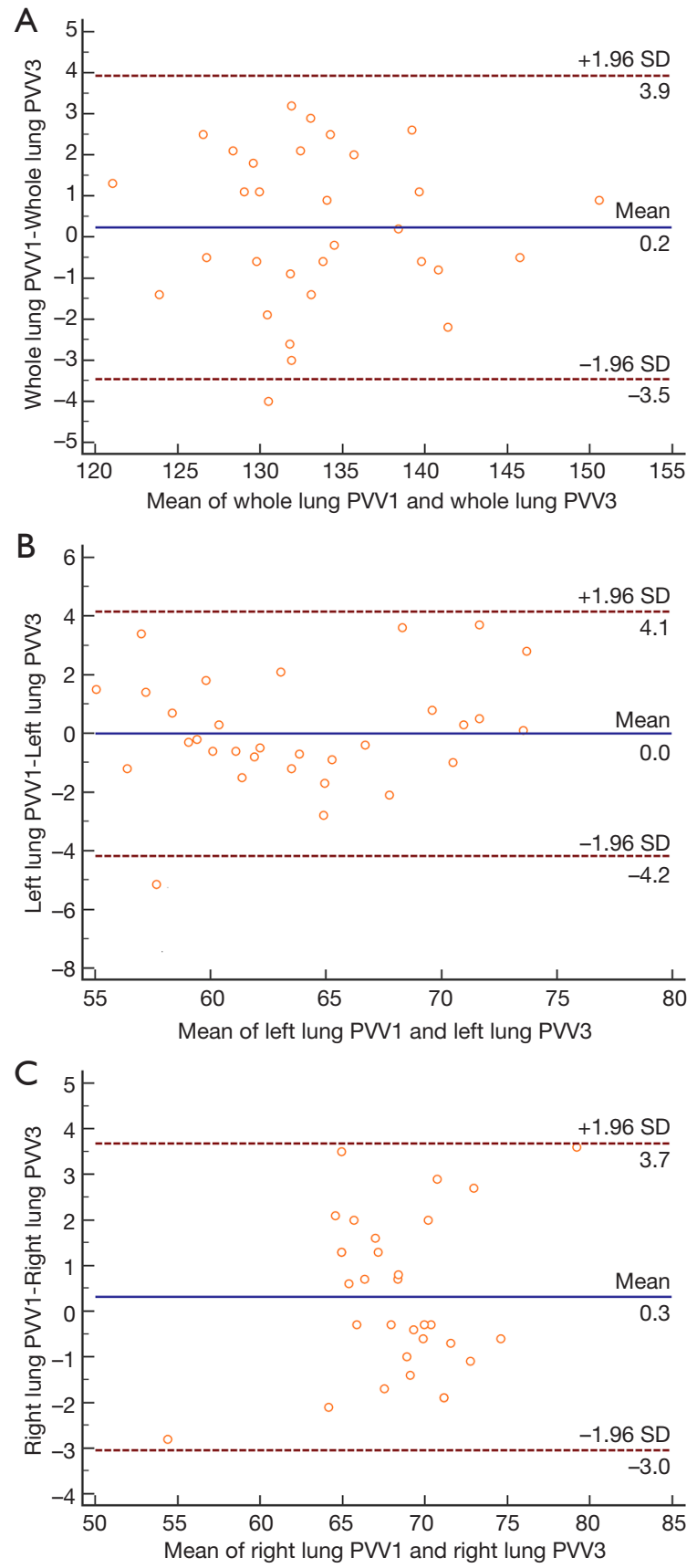

Figure 4 Bland-Altman plots of PVVs measurements by 1 observer twice in 1 month. (A) A Bland-Altman plot of the whole lung PVVs (as measured by 1 observer twice in 1 month) demonstrated a bias of 0.2. (B) A Bland-Altman plot of left lung PVVs (as measured by 1 observer twice in 1 month) demonstrated a bias of 0 . (C) A Bland-Altman plot of right lung PVVs (as measured by 1 observer twice in 1 month) demonstrated a bias of 0.3. PVV1 and PVV3 represent the PVVs measured by observer 1 the first time and second time after 1 month, respectively. 
Table 2 Pulmonary vascular volumes of non-smokers in different age groups

\begin{tabular}{|c|c|c|c|c|c|c|}
\hline PVVs (mL) & $40-49$ years $(n=66)$ & $50-59$ years $(n=324)$ & $60-69$ years $(n=172)$ & $\geq 70$ years $(n=158)$ & $\mathrm{F}$ & $\mathrm{P}$ \\
\hline Right lung & $69.7 \pm 11.3^{\mathrm{bcd}}$ & $67.8 \pm 14.2^{\mathrm{acd}}$ & $61.5 \pm 13.6^{\mathrm{abd}}$ & $58.7 \pm 12.9^{\mathrm{abc}}$ & 105.79 & $<0.001$ \\
\hline Left lung & $62.4 \pm 9.8^{\mathrm{bcd}}$ & $58.7 \pm 12.1^{\mathrm{acd}}$ & $52.7 \pm 11.5^{\mathrm{abd}}$ & $50.3 \pm 10.2^{\mathrm{abc}}$ & 65.62 & $<0.001$ \\
\hline Right upper lobe & $23.9 \pm 2.6^{\mathrm{cd}}$ & $23.6 \pm 3.2^{\mathrm{cd}}$ & $21.3 \pm 3.6^{\mathrm{ab}}$ & $21.9 \pm 1.5^{\mathrm{ab}}$ & 30.04 & $<0.001$ \\
\hline Right lower lobe & $36.5 \pm 3.3^{\mathrm{bcd}}$ & $33.9 \pm 5.3^{\mathrm{acd}}$ & $30.5 \pm 3.5^{\mathrm{abd}}$ & $28.4 \pm 1.2^{\mathrm{abc}}$ & 96.08 & $<0.001$ \\
\hline Left upper lobe & $27.9 \pm 2.7^{\mathrm{cd}}$ & $28.0 \pm 3.3^{\mathrm{cd}}$ & $26.3 \pm 2.7^{\mathrm{abd}}$ & $25.6 \pm 1.2^{\mathrm{abc}}$ & 34.29 & $<0.001$ \\
\hline Left lower lobe & $33.8 \pm 3.6^{\mathrm{bcd}}$ & $30.2 \pm 3.7^{\text {acd }}$ & $26.5 \pm 3.2^{\mathrm{abd}}$ & $25.7 \pm 1.3^{\mathrm{abc}}$ & 153.03 & $<0.001$ \\
\hline
\end{tabular}

LSD-t test: $a: P<0.05$ vs. $\leq 49$ years; b: $\mathrm{P}<0.05$ : vs. $50-59$ years; $c$ : $P<0.05$ vs. $60-69$ years; $d: P<0.05$ vs. $\geq 70$ years; the 1 -wayANOVA test with $\mathrm{F}$ value. PVVs, pulmonary vascular volumes.

Table 3 The effect of smoking status on pulmonary vascular volumes

\begin{tabular}{|c|c|c|c|c|c|c|}
\hline PVVs (mL) & Non-smokers $(n=720)$ & Light smokers $(n=184)$ & ) Heavy smokers ( $n=261)$ & Ex-smokers $(n=155)$ & $\mathrm{F}$ & $P$ \\
\hline Right lung & $64.3 \pm 7.6^{\mathrm{bcd}}$ & $69.6 \pm 6.1^{\mathrm{ac}}$ & $78.3 \pm 7.4^{\mathrm{abd}}$ & $69.1 \pm 7.2^{\mathrm{ac}}$ & 237.2 & $<0.001$ \\
\hline Right upper lobe & $22.7 \pm 3.1^{\mathrm{bcd}}$ & $24.4 \pm 3.1^{\text {acd }}$ & $26.7 \pm 4.2^{\mathrm{abd}}$ & $25.3 \pm 3.7^{\mathrm{abc}}$ & 96.8 & $<0.001$ \\
\hline Right middle lobe & $9.7 \pm 1.6^{\mathrm{bcd}}$ & $10.6 \pm 1.6^{\mathrm{ac}}$ & $13.5 \pm 2.9^{\mathrm{abd}}$ & $10.6 \pm 1.4^{\mathrm{ac}}$ & 257.6 & $<0.001$ \\
\hline Left lung & $55.9 \pm 7.8^{\mathrm{bcd}}$ & $61.1 \pm 5.8^{\mathrm{ac}}$ & $66.9 \pm 7.4^{\mathrm{abd}}$ & $60.0 \pm 6.0^{\mathrm{ac}}$ & 151.2 & $<0.001$ \\
\hline Left upper lobe & $27.1 \pm 3.0^{\mathrm{bcd}}$ & $28.8 \pm 3.5^{\mathrm{ac}}$ & $30.4 \pm 4.7^{\mathrm{abd}}$ & $29.3 \pm 3.1^{\mathrm{ac}}$ & 65.7 & $<0.001$ \\
\hline Left lower lobe & $28.7 \pm 4.1^{\mathrm{bcd}}$ & $32.2 \pm 4.6^{\text {acd }}$ & $36.8 \pm 4.3^{\mathrm{abd}}$ & $30.2 \pm 4.8^{\mathrm{abc}}$ & 233.4 & $<0.001$ \\
\hline
\end{tabular}

LSD-t test: a: vs. non-smokers, $\mathrm{P}<0.05$; b: vs. light smokers, $\mathrm{P}<0.05$; $\mathrm{c}$ : vs. heavy smokers, $\mathrm{P}<0.05$; $\mathrm{d}$ : vs. ex-smokers, $\mathrm{P}<0.05$; the

1-wayANOVA test with F value. PVVs, pulmonary vascular volumes.

CI: $0.95-0.99), 0.96$ (95\% CI: 0.95-0.99), and 0.96 (95\%

CI: 0.92-0.98), respectively.

\section{The effects of aging and smoking on PVVs}

As Table 2 shows, in healthy male non-smokers, the PVVs of the whole lung, right lung, left lung, and bilateral lower lobes decreased with age. However, the PVVs of the bilateral upper lobes were similar between the 40-49, $50-59,60-69$, and the $\geq 70$-year-old groups.

As Table 3 shows, the heavy smokers had the greatest PVVs, followed by the light smokers and the ex-smokers, and the non-smokers had the smallest PVVs. The PVVs were comparable between the ex-smokers and the light smokers. As Figure 5 shows, in each age group, the heavy smokers had the greatest PVVs, followed by the light smokers and ex-smokers, and non-smokers had the smallest PVVs.

\section{Discussion}

This study quantitatively measured PVVs on LDCT in a Chinese male population and found several interesting findings for this large cohort. First, the quantitative measurement of LDCT-derived PVVs with an automatic integration segmentation approach is reproducible. Second, PVVs decreased with age in male non-smokers. Third, PVVs was more increased in smokers than non-smokers.

Morphometric information of the pulmonary vasculature of healthy subjects is necessary to improve understandings of physiological aging and pathologic deviations beyond the normal variation expected between subjects. Pienn 

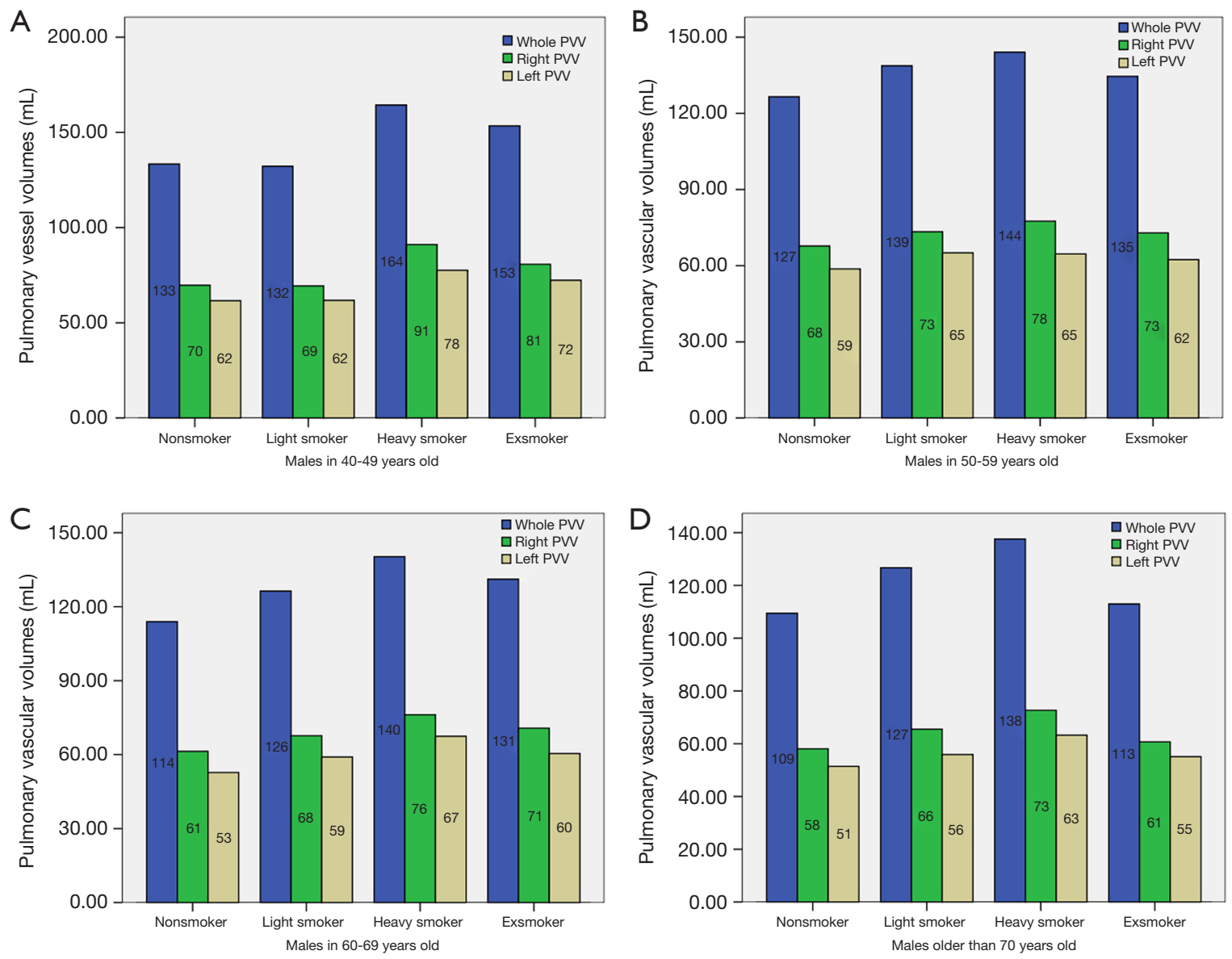

Figure 5 The effects of smoking status on PVVs in different age groups. PVVs of the whole lung, right lung, and left lung in males aged (A) 40-49 years old; (B) 50-59 years old; (C) 60-69 years old; and (D) more than 70 years old, respectively.

et al. (19) determined the number and volume of pulmonary vessels (with a diameter range between 2 and $10 \mathrm{~mm}$ ) with CT pulmonary angiography datasets. Previous studies have examined alterations in the pulmonary vasculature, as assessed using a 2-dimensional cross-sectional area of the small vessels in axial CT images in patients with COPD (20-23) and non-smokers (24). Recently, LDCT has been used to quantitatively evaluate COPD, asthma, and interstitial lung disease, as well as lung cancer (9,25-27). Jun (13) demonstrated that an automatic integration segmentation approach could provide much better and lower-level vascular branches in LDCT scans. In our health check-up population, PVVs were also measured on LDCT scans. The automatic integration segmentation approach and the segmentation algorithm provided reproducible measurements of PVVs on LDCT scans.

Previous studies $(28,29)$ have shown that a thickening of the intima characterizes vascular aging, decreased elasticity, and a decreasing number of capillaries. However, very few studies have reported on the manifestation of pulmonary vascular aging on CT scans. We compared the PVVs among healthy male non-smokers of different ages and found that PVVs of the whole lung, left lung, right lung, and 5 lung lobes decreased with age. Using the manual counting method, Wang et al. $(30,31)$ reported that the number of small pulmonary vessels were decreased in subjects older than 40 years of age; however, Wang et al. did not evaluate pulmonary vascular aging overall. The present study showed that a decrease in PVV characterized pulmonary vascular aging in non-smokers. Additionally, our subgroup analysis of different age groups showed that differences in PVVs were low in the upper lobe but high in the lower lobe. This may indicate that the lower lobes age faster than the upper lobes; however, the mechanism by which this 
occurs is unclear.

Histologically, tobacco-related vasculopathy is characterized by vessel narrowing and loss (32-34); however, in our study, the PVVs of non-smokers, light smokers, and heavy smokers gradually increased. Cigarette exposure was also found to be associated with higher pulmonary blood vessel volumes, especially in the smaller peripheral vessels, in the Framingham Heart Study (8). Smoking can cause pulmonary vascular wall thickening and remodeling; thus, we speculate that the increase of PVVs in smokers is due to the thickening of the pulmonary vascular wall. We also found that the PVVs of ex-smokers were lower than those of heavy smokers and similar to those of light smokers but higher than those of non-smokers. Similarly, in the MESA Study, ever-smokers were found to have a higher total PVVs than never-smokers (7). These results suggest that smoking cessation may slow pulmonary vascular remodeling.

This study had several limitations. First, as the number of female smokers and ex-smokers was small, PVVs in the female population and the difference of PVVs between males and females could not be studied and remains unknown. Second, as this is a single-center retrospective study, it should be noted that the male participants who presented for routine health check-up visits may not necessarily be representative of the broader population of China. Thus, the establishment of reference values requires a broader population study. Third, as body surface area and the detailed lung function metrics were not detailed in the health reports, we could only compare the absolute value of PVVs in different groups; thus, correlations between PVVs and lung function require further study. Fourth, while we compared PVVs in non-smokers, ever-smokers, and smokers, the effects of other factors, such as second-hand tobacco exposure, socioeconomic status, and occupation, on PVVs remain unknown and should be considered in future prospective studies. Fifth, as LDCT scans have the increased density noise, the misclassification of a single vascular voxel can cause the segmentation to break away the branches of low-level vessels and result in them being classified as lung parenchyma tissues. To address this issue, we used a soft 3D Gaussian kernel filter to reduce density noise. However, vessel density decreases substantially as vascular diameter decreases, and the partial volume effects reduce the contrast between the lower-level vessels and the parenchyma. This makes low-level vessel detection very difficult in LDCT. Sixth, as the PVVs evaluated by LDCT do not show the pulmonary microvasculature or distinguish between the pulmonary artery and pulmonary vein, the effects of smoking on pulmonary arteries, veins, and microvasculature cannot be independently evaluated on LDCT. Finally, smokers' lung function needs to be assessed, and correlations between PVVs, emphysema and lung function will be analyzed in the further study.

\section{Conclusions}

Our study showed that PVVs (as measured on LDCT) gradually decreased with age in non-smokers. Compared to non-smokers, the PVVs of smokers increased, even with normal lung function.

\section{Acknowledgments}

Funding: This work was supported by the Beijing Nature Science Foundation (Grant No. 7182149), the National Natural Science Foundation of China (Grant No. 81871328), the Youth Talents Project of Chinese Academy of Medical Science (Grant No. 2018RC320013), and the Beijing Science and Technology Commission Pharmaceutical and Technology Innovation Project (Grant No. Z18110000 1918034).

\section{Foonote}

Conflicts of Interest: All authors have completed the ICMJE uniform disclosure form (available at https://dx.doi. org/10.21037/qims-21-160). The authors have no conflicts of interest to declare.

Ethical Statement: The authors are accountable for all aspects of the work, including ensuring that any questions related to the accuracy or integrity of any part of the work have been appropriately investigated and resolved. The study was approved by the Ethics Committee of the China-Japan Friend Hospital (IRB 2019-123-K85-1). The study was conducted in accordance with the Declaration of Helsinki (as revised in 2013). Informed consent was obtained from all patients.

Open Access Statement: This is an Open Access article distributed in accordance with the Creative Commons Attribution-NonCommercial-NoDerivs 4.0 International License (CC BY-NC-ND 4.0), which permits the noncommercial replication and distribution of the article with the strict proviso that no changes or edits are made and the original work is properly cited (including links to both the 
formal publication through the relevant DOI and the license). See: https://creativecommons.org/licenses/by-nc-nd/4.0/.

\section{References}

1. Lowery EM, Brubaker AL, Kuhlmann E, Kovacs EJ. The aging lung. Clin Interv Aging 2013;8:1489-96.

2. World Health Organization. Tobacco Control Country Profile. WHO, Geneva 2003.

3. Li XG, Zhou HY. A handbook for tobacco control reporting. Tsing Hua University Press 2008:1.

4. Ferrer E, Peinado VI, Castañeda J, Prieto-Lloret J, Olea E, González-Martín MC, Vega-Agapito MV, Díez M, Domínguez-Fandos D, Obeso $\mathrm{A}$, González C, Barberà JA. Effects of cigarette smoke and hypoxia on pulmonary circulation in the guinea pig. Eur Respir J 2011;38:617-27.

5. Nathan SD, Barbera JA, Gaine SP, Harari S, Martinez FJ, Olschewski H, Olsson KM, Peacock AJ, Pepke-Zaba J, Provencher S, Weissmann N, Seeger W. Pulmonary hypertension in chronic lung disease and hypoxia. Eur Respir J 2019;53:1801914.

6. Rahman I, Adcock IM. Oxidative stress and redox regulation of lung inflammation in COPD. Eur Respir J 2006;28:219-42.

7. Aaron CP, Hoffman EA, Lima JAC, Kawut SM, Bertoni AG, Vogel-Claussen J, et al. Pulmonary vascular volume, impaired left ventricular filling and dyspnea: The MESA Lung Study. PLoS One 2017;12:e0176180.

8. Synn AJ, Zhang C, Washko GR, Estépar RSJ, O'Connor GT, Li W, Mittleman MA, Rice MB. Cigarette Smoke Exposure and Radiographic Pulmonary Vascular Morphology in the Framingham Heart Study. Ann Am Thorac Soc 2019;16:698-706.

9. Heuvelmans MA, Vonder M, Rook M, Groen HJM, De Bock GH, Xie X, Ijzerman MJ, Vliegenthart R, Oudkerk M. Screening for Early Lung Cancer, Chronic Obstructive Pulmonary Disease, and Cardiovascular Disease (the Big-3) Using Low-dose Chest Computed Tomography: Current Evidence and Technical Considerations. J Thorac Imaging 2019;34:160-9.

10. Spinnato P. Low-Dose Computed Tomography Screening Proposal for the "Big-3 Diseases": Lung Cancer, Chronic Obstructive Pulmonary Disease, and Cardiovascular Disease. Acad Radiol 2021;28:46-8.

11. Sadate A, Occean BV, Beregi JP, Hamard A, Addala T, de Forges H, Fabbro-Peray P, Frandon J. Systematic review and meta-analysis on the impact of lung cancer screening by low-dose computed tomography. Eur J Cancer
2020;134:107-14.

12. Tan W, Yuan Y, Chen A, Mao L, Ke Y, Lv X. An Approach for Pulmonary Vascular Extraction from Chest CT Images. J Healthc Eng 2019;2019:9712970.

13. Jun Lai, Ying Huang, Ying Wang,Jun Wan. ThreeDimension Segmentation of Pulmonary Vascular Trees for Low Dose CT Scans. SENS IMAGING 2016;17:13

14. Bellomi M, Rampinelli C, Veronesi G, Harari S, Lanfranchi F, Raimondi S, Maisonneuve P. Evolution of emphysema in relation to smoking. Eur Radiol 2010;20:286-92.

15. Pu J, Roos J, Yi CA, Napel S, Rubin GD, Paik DS. Adaptive border marching algorithm: automatic lung segmentation on chest CT images. Comput Med Imaging Graph 2008;32:452-62.

16. Pu J, Leader JK, Zheng B, Knollmann F, Fuhrman C, Sciurba FC, Gur D. A Computational geometry approach to automated pulmonary fissure segmentation in CT examinations. IEEE Trans Med Imaging 2009;28:710-9.

17. Pu J, Zheng B, Leader JK, Fuhrman C, Knollmann F, Klym A, Gur D. Pulmonary lobe segmentation in CT examinations using implicit surface fitting. IEEE Trans Med Imaging 2009;28:1986-96.

18. Yu N, Yuan H, Duan HF, Ma JC, Ma GM, Guo YM, Wu F. Determination of vascular alteration in smokers by quantitative computed tomography measurements. Medicine (Baltimore) 2019;98:e14438.

19. Pienn M, Burgard C, Payer C, Avian A, Urschler M, Stollberger R, Olschewski A, Olschewski H, Johnson T, Meinel FG, Bálint Z. Healthy Lung Vessel Morphology Derived From Thoracic Computed Tomography. Front Physiol 2018;9:346.

20. Matsuura Y, Kawata N, Yanagawa N, Sugiura T, Sakurai Y, Sato M, Iesato K, Terada J, Sakao S, Tada Y, Tanabe N, Suzuki Y, Tatsumi K. Quantitative assessment of crosssectional area of small pulmonary vessels in patients with COPD using inspiratory and expiratory MDCT. Eur J Radiol 2013;82:1804-10.

21. Matsuoka S, Washko GR, Yamashiro T, Estepar RS, Diaz A, Silverman EK, Hoffman E, Fessler HE, Criner GJ, Marchetti N, Scharf SM, Martinez FJ, Reilly JJ, Hatabu H; National Emphysema Treatment Trial Research Group. Pulmonary hypertension and computed tomography measurement of small pulmonary vessels in severe emphysema. Am J Respir Crit Care Med 2010;181:218-25.

22. Matsuoka S, Washko GR, Dransfield MT, Yamashiro T, San Jose Estepar R, Diaz A, Silverman EK, Patz S, Hatabu H. Quantitative CT measurement of cross-sectional 
area of small pulmonary vessel in COPD: correlations with emphysema and airflow limitation. Acad Radiol 2010;17:93-9.

23. Coste F, Dournes G, Dromer C, Blanchard E, FreundMichel V, Girodet PO, Montaudon M, Baldacci F, Picard F, Marthan R, Berger P, Laurent F. CT evaluation of small pulmonary vessels area in patients with COPD with severe pulmonary hypertension. Thorax 2016;71:830-7.

24. Uejima I, Matsuoka S, Yamashiro T, Yagihashi K, Kurihara Y, Nakajima Y. Quantitative computed tomographic measurement of a cross-sectional area of a small pulmonary vessel in nonsmokers without airflow limitation. Jpn J Radiol 2011;29:251-5.

25. Bastarrika G, Wisnivesky JP, Pueyo JC, Díaz L, Arraiza M, Villanueva A, Alcaide AB, Campo A, Seijo L, de Torres JP, Zulueta JJ. Low-dose volumetric computed tomography for quantification of emphysema in asymptomatic smokers participating in an early lung cancer detection trial. J Thorac Imaging 2009;24:206-11.

26. Chen H, Zeng QS, Zhang M, Chen RC, Xia TT, Wang W, Xu X, Guan Y. Quantitative Low-Dose Computed Tomography of the Lung Parenchyma and Airways for the Differentiation between Chronic Obstructive Pulmonary Disease and Asthma Patients. Respiration 2017;94:366-74.

27. Xu X, Sui X, Song L, Huang Y, Ge Y, Jin Z, Song W. Feasibility of low-dose CT with spectral shaping and third-generation iterative reconstruction in evaluating interstitial lung diseases associated with connective tissue disease: an intra-individual comparison study. Eur Radiol 2019;29:4529-37.

28. Dantas AP, Jiménez-Altayó F, Vila E. Vascular aging: facts and factors. Front Physiol 2012;3:325.

29. Ungvari Z, Tarantini S, Donato AJ, Galvan V, Csiszar A. Mechanisms of Vascular Aging. Circ Res 2018;123:849-67.

30. Wang LH, Li RM, Guo YM. CT Study of the Diameter and Distribution Character of Pulmonary Small Vessels. Chin J Med Imaging Technol 2003;19:1613-7.

31. Wang LH, Li RM, Guo YM, Yang J, Niu G, Liu JH. CT study of branching characters of pulmonary small vessels. Chin J Radiol 2003;37:1097-100.

32. Hale KA, Niewoehner DE, Cosio MG. Morphologic changes in the muscular pulmonary arteries: relationship to cigarette smoking, airway disease, and emphysema. Am Rev Respir Dis 1980;122:273-8.

33. Ferrer E, Peinado VI, Díez M, Carrasco JL, Musri MM, Martínez A, Rodríguez-Roisin R, Barberà JA. Effects of cigarette smoke on endothelial function of pulmonary arteries in the guinea pig. Respir Res 2009;10:76.

34. Fira-Mladinescu O, Noveanu L, Ordodi V, FiraMladinescu C, Tudorache V, Mihalaş G. The effects of chronic exposure to cigarette smoke on vasomotor endothelial function of guinea pig pulmonary arteries. Rev Med Chir Soc Med Nat Iasi 2008;112:213-9.
Cite this article as: Sun $\mathrm{X}$, Meng $\mathrm{X}$, Zhang $\mathrm{P}$, Wang L, Ren Y, Xu G, Yang T, Liu M. Quantification of pulmonary vessel volumes on low-dose computed tomography in a healthy male Chinese population: the effects of aging and smoking. Quant Imaging Med Surg 2022;12(1):406-416. doi: 10.21037/ qims-21-160 